\title{
Gamma radiation to produce soybean mutants for better plant performance and chemical composition of seeds
}

\author{
Danúbia Aparecida Costa Nobre ${ }^{1 *}$, Carlos Sigueyuki Sediyama², Willian Rodrigues Macedo, \\ Newton Deniz Piovesan ${ }^{3}$, Valter Arthur ${ }^{4}$ \\ ${ }^{1}$ Institute of Agricultural Science, Universidade Federal de Viçosa, Rio Paranaíba, Minas Gerais, Brazil, ${ }^{2}$ Department Plant Science, \\ Universidade Federal de Viçosa, Viçosa, Minas Gerais, Brazil, ${ }^{3}$ nstitute of Biotechnology Applied to Agriculture, Universidade Federal de \\ Viçosa, Viçosa, Minas Gerais, Brazil, ${ }^{4}$ Center for Nuclear Energy in Agriculture, Universidade de São Paulo, Piracicaba, São Paulo, Brazil
}

\section{A B S T R A C T}

\begin{abstract}
The supply the constant demand for new soybean cultivar, it is necessary to select superior plants in populations of high genetic variability. To generate new plant variants which would perform satisfactorily in the field and produce seeds of better composition, gamma rays can be used. Therefore, soybean seeds from line VX04-6828 were irradiated in a ${ }^{60} \mathrm{Co}$ source (gamma rays) in doses: 0 (control); $50 ; 150$ and $250 \mathrm{~Gy}$, and were seeded to produce the M1 generation. Potential plants of each row were identified and evaluated for their agronomic performance. The seeds of the selected plants were sown, producing the plants of M2 generation and again selected and evaluated, including the chemical composition of their seeds. It was concluded that the use of gamma radiation increases the variability in soybean, with consequent increase in the probabilities of identification of new mutants, useful to breeding programs that aim at better agronomic performance and gains in the composition of the seeds. Better results are observed when 50 to 150 Gy is applied on soybean dry seeds.
\end{abstract}

Keywords: Chemical composition; Gamma rays; Glycine max; Infrared spectroscopy

\section{INTRODUCTION}

The increase in soybean planting area is linked to its use in human and animal feeding, because its seeds present high levels of protein ( 37 to $42 \%$ ) and oil (17 to $22 \%$ ), besides other components, especially isoflavones, which have a potential inhibitory effect on the growth of cells and enzymes involved in carcinogenic processes (Barnes, 1995; Sediyama, 2013; 2016).

The widespread use of soybeans and their coproducts, raises the demand of new cultivars with the most favorable characteristics. The selection of new cultivars depends fundamentally on the genetic variability and mutations. The natural frequency of mutations is about $10^{-6}$ per generation, but may reach the order of $10^{-3}$ when the genetic material is subjected to the use of physical agents, such as gamma rays; the frequency of mutations is also proportional to the applied dose of rays (Borém and Miranda, 2013).

The genetic variability depends on the survival of the individual and on the stability of their genome. The stability of a genome depends on replication and repair mechanisms of the damages that constantly occur in the structure of deoxyribonucleic acid - DNA (Costa et al., 2001; Morita et al. 2010). However, the use of mutagens, such as gamma rays, offer great possibilities for increasing genetic variability by the creation and incorporation of new genes of agronomic interest such as yield (Tulmann Neto et al. 1995; Jan et al., 2012; Ramchander et al., 2015).

Soybean yield and quality characteristics (oil content and high protein levels) have been increased through selection efforts in breeding programs (Bruce et al. 2019). However, there are different market demands, such as obtaining resistance to diseases and pest insects, adapting to abiotic stresses and improving nutritional quality (Dall’Agnol, 2016).

The use of gamma radiation in soybean has allowed to identify mutant strains with several characteristics favorable to the use for human food, such as strains with lower levels of antinutritional factors and better sensory quality (Dixit et al., 2011; Lee et al., 2011), in addition, innumerable

\footnotetext{
*Corresponding author:

Danúbia Aparecida Costa Nobre, Institute of Agricultural Science, Universidade Federal de Viçosa, Rio Paranaíba, Minas Gerais, Brazil.

E-mail: danubia_nobre@yahoo.com.br
}

Received: 21 March 2019; Accepted: 18 June 2019 
gains in biological parameters for the soybean plant and generation of genetic variability have been offered through induced mutation, which is highly effective and useful, as mutations are transmitted to the next ones. generations, may drive the evolution of the adaptive genome and generate other new beneficial characteristics (Verma et al., 2018; Lande et al., 2018; El-Azabs et al. 2018).

Interestingly, soybean seed chemical composition is an important determinant in the economic value of the crop, since soybean is mainly utilized in feeding and manufacturing of industrial products (Patil et al., 2017). The use of techniques that facilitate the evaluation of these components such as NIR, has been demonstrated (Basoni et al., 2017; Wee et al., 2018).

In view of this, the objectives of this study were to increase soybean genetic variability and the chances of identifying presumed mutants with better agronomic characteristics and seeds with superior chemical composition.

\section{MATERIALS AND METHODS}

Seeds of VX04-6828 soybean line at the final stage of the breeding program, with a water content of approximately $12.0 \%$, were irradiated with doses of 0 (control), 50, 150 and $250 \mathrm{~Gy}$ of gamma radiation from of a source of ${ }^{60} \mathrm{Co}$, Gammacell-220, under dose rate of $0.312 \mathrm{kGy} / \mathrm{h}$.

The irradiated seeds were sown at $20^{\circ} 46^{\prime}$ south latitude, $42^{\circ} 52^{\prime}$ west longitude and $648 \mathrm{~m}$ altitude. The soil of the study area is classified as Red-Yellow Argisol (PVA), of clay texture. The 08-28-16 formulated fertilizer was applied in the sowing furrow at a dose of $300 \mathrm{~kg} \mathrm{ha}^{-1}$.

The field trial was carried out in a randomized block design, with three replications, each plot consisting of a 20 meters row, with 15 seeds per meter, totaling 300 seeds of each treatment of irradiation and lineage, which gave origin to the plants of the M1 generation ( $1^{\text {st }}$ generation after irradiation). Cultural practices were applied as needed. From this planting, 90 plants per row were identified, on which, plant performance evaluations were performed, and the 72 best plants of each treatment were selected to produce the M2 generation (Figure S1).

In the following agricultural year, thirty M2 seeds from each of the 72 selected plants of each treatment were sown in rows of 2 meters each, spaced at $0.70 \mathrm{~cm}$, in three randomized blocks. At 21 days after sowing, thinning was performed, maintaining 20 plants per line. Both M1 and M2 generations were submitted to daily observations on emerged seedlings until the $21^{\text {st }}$ day after sowing, to identify chlorotic plants and, at the end of the experiment, to evaluate the sterile plants.

Ten plants of each row were identified, totaling 720 plants, which were individually evaluated for their performance through the following characteristics: Plant height at full flowering (R2), height of insertion of the first pod, and height of plants at maturity (R8), in centimeters; number of nodes on the main stem; number of pods with zero, one, two, three or four seeds; weight of one hundred seeds; number of seeds per plant, seeds per pod and pods per plant.

Plants with the greatest number and weight of seeds were selected, totaling 552 plants. The chemical quality of the soybean seeds was evaluated by means of their content of protein, oil, oleic acid, linolenic acid, linoleic acid, stachyose, sucrose, raffinose and total sugars. Twenty-five seeds of each plant were harvested in three replicates, which were milled (MA20 model mill with a 10-mesh sieve), and the flours were subjected to near-infrared spectrometry (NIR).

The results were presented by means of boxplot diagrams, for a better visualization of the distribution of the different variables under study, and those that differed by the analysis of variance, presented in regression, by means of the computational statistical software " $R$ " (R Core Team, 2015).

\section{RESULTS AND DISCUSSION}

The characteristics evaluated in the M2 generation, indicated that there is variation between the plants in the different doses of gamma rays, which denotes potential for the process of genetic improvement, since it points out the existence of variability necessary for the selection of superior genotypes.

The distribution of the data originated by the evaluated agronomic characteristics is presented on Figures 1 to 6 by means of boxplots, which allow to verify in a simple and fast way the distinction and the general behavior of populations. The "box" shows the range containing the $50 \%$ of the data, with the median indicated by a transverse line; the data that extrapolate the box, limited by the "whiskers" are the values of maximum and minimum "fences", defined by the limits of the amplitude of the box; the "outliers", that is, the values that go beyond these fences, are represented by the circles in the prolongation of the "whiskers" (Wickham and Stryjewski, 2011; Krzywinski and Altman, 2014). In the present study, they suggest possible mutations in the genes that determine the given characteristic. 
The highest value measured on the control (0 Gy) for each of the evaluated variable was used to compare the maximum mean of each treatment (50,150 and $250 \mathrm{~Gy}$ ), including the outliers, and the percentage gains was given at each dose of gamma ray applied.

In Figure 1 we find the boxplots of the plant height data at full bloom (A) and at maturity of soybean (B), in centimeters $(\mathrm{cm})$. In both figures, we notice the presence of outliers.

These differentiated behaviors of the lineages are inherent to their respective genetic constitutions for greater or lesser susceptibility to the effects of radiation, since previous studies had already detected reduction in the height of soybean plants with the increase of gamma radiation (Mudibu et al., 2012; Sarker et al., 2014). In addition, the highest plant height presented by the VX04-6828 strain at full maturity results from the fact that it presents semi- determined growth, that is, its growth continues even after the onset of axillary or terminal flowering (Sediyama, 2016).

Gains of the order of 2.0 and $22.0 \%$ were observed for the doses of 50 and $150 \mathrm{~Gy}$, respectively, and no increase for the dose of $250 \mathrm{~Gy}$, in height of plants at full flowering. As for maturity height, the gains were 19.6; 17.5 and $9.3 \%$, for the doses of 50,150 and $250 \mathrm{~Gy}$, respectively. These increments can imply in higher final crop production, since the growing plant guarantees a greater number of nodes, lateral stems, leaf area and, finally, greater photosynthetic capacity (Sediyama, 2016).

Figure 2 refers to the height of the first pod insertion (A) and number of nodes in soybean plants (B). For height of insertion of the first pod, we can see gains of $20.0 ; 12.0$ and $8.0 \%$ at doses of 50, 150 and 250 Gy, respectively. This can impart increased productivity depending on the harvest range of the cutting platform.

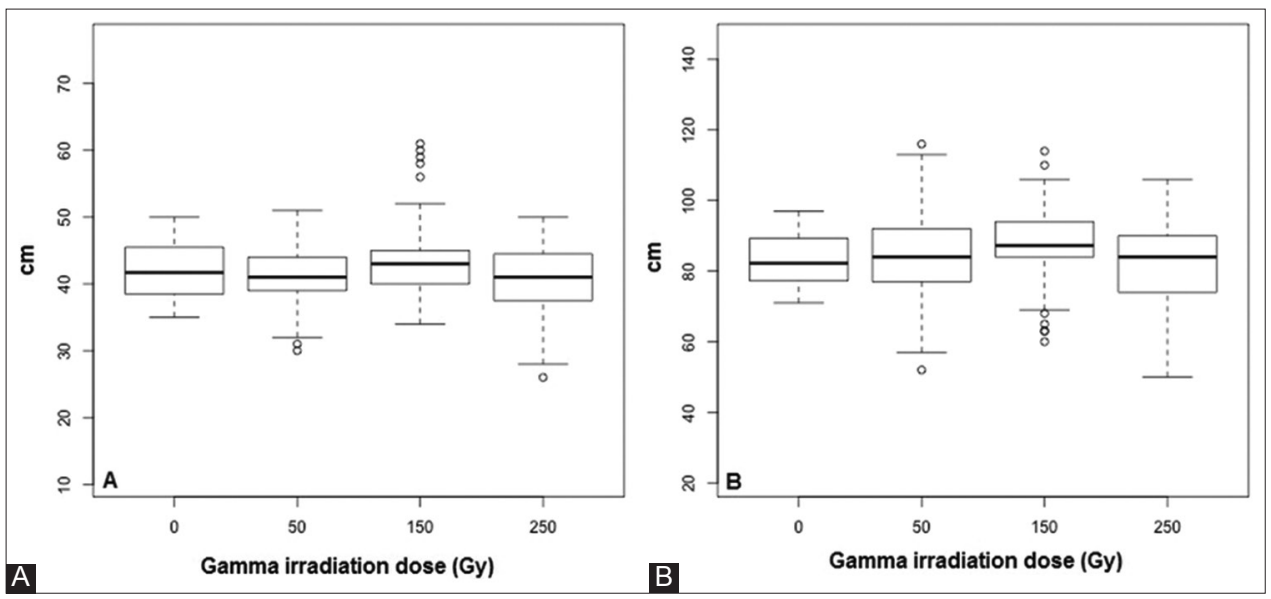

Fig 1. Boxplot of plant height data at full bloom (A) and at maturity of soybean (B), in centimeters (cm), submitted to doses of gamma radiation (Gy).

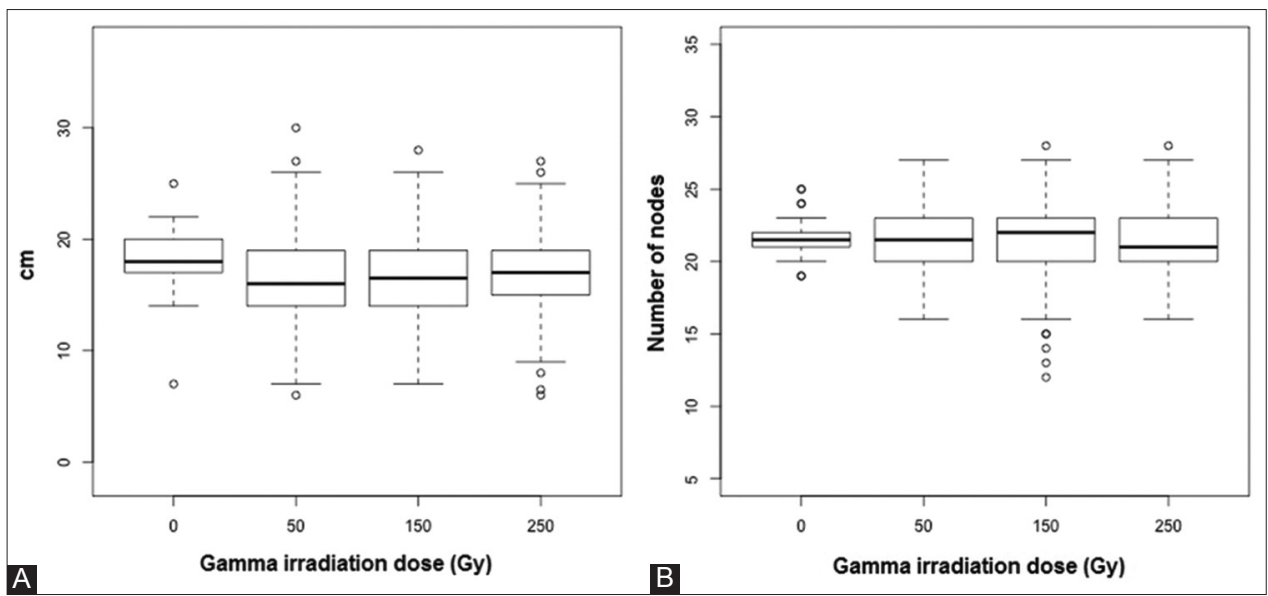

Fig 2. Boxplot for the data of height of insertion of the first pod (A), in centimeters (cm), and number of nodes in soybean plants (B), submitted to doses of gamma radiation (Gy). 
The percent gains for the number of nodes were $8.0 \%$ for $50 \mathrm{~Gy}$ and $12.0 \%$ for 150 and $250 \mathrm{~Gy}$ (Fig. 2). The increase in number of nodes of soybean plants implies an increase of productive branches, which can also interfere positively in the final yield of the crop.

Figure 3 expresses the number of pods with one, two, three, four seeds and empty pods per plant (A, B, C, D and E, respectively) at the evaluated gamma dose rates.

For the variables presented on Figure 3, the number of pods with one seed (A) obtained gains of the order of 107.7; 296.2 and $119.2 \%$ at the doses of 50, 150 and
250 Gy, respectively, which constitutes a disadvantage for final crop production. For the other variables, increases were also observed, higher than $33.0 \%$, except for pods with four seeds, at dosages of 50 and 250 Gy. It was also observed the increase in the frequency of outliers, at the doses of gamma radiation for the analyzed variables indicating punctual changes for some plants.

In the graph of Fig. 3 (B, C and E), similar distributions were presented, with an increase in the amplitude of variation of the central $50 \%$ stratum, with the application of gamma radiation, with direct indication of changes in genetic structures or physiological processes of the plants.

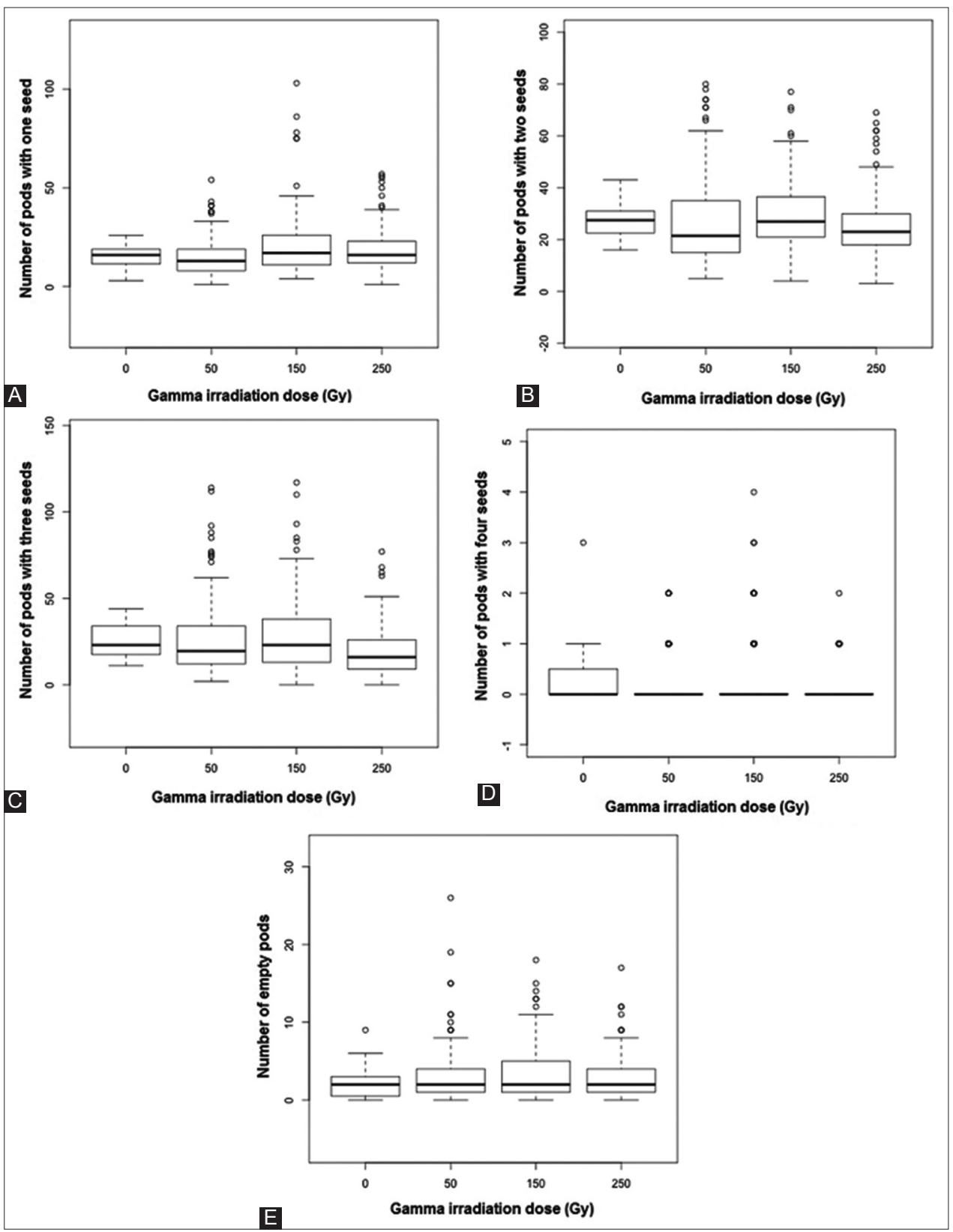

Fig 3. Boxplot of the number of pods with one (A), two (B), three $(C)$ and four seeds $(D)$, and empty pods $(E)$ on soybean plants submitted to gamma radiation doses (Gy). 
On the other hand, for the variable number of pods with four seeds (D), no increased amplitude was observed with the use of gamma radiation.

According to Bizeti et al. (2004), soybeans may increase or decrease the number of seeds as a function of their size, as a kind of buffer effect, without significant variation in grain yield, nevertheless, in the present study, the use of gamma rays increased variability of these characteristics.

The use of gamma rays seems to favor the increase of the formation of pods in soybean plants. It is observed a greater variability, which can also be observed by the greater number of outliers (Fig. E).

The distribution of the number of seeds per pod (A) and seeds per plant (B), when submitted to doses of gamma rays (Fig. 4), like the distribution of pods with different seed numbers, showed increased variability with the application of gamma radiation from $50 \mathrm{~Gy}$, with the appearance of a greater number of outliers for number of seeds per pod and number of seeds per soybean plant, indicating possible genetic alteration, that is, possible mutation.

For the variables seeds per pod (A) and weight of 100 seeds (B), according to Figure 5, it is observed an increase in the variability in both variables with the application of gamma radiation as well as an increase in the frequency of outliers.

The boxplots of Figure 5 show for pods per plant (A), variation in the amplitude of the $50 \%$ of the central data, with slight increase of the median of the order of $4.5 ; 4.1$ and $1.6 \%$ in comparison to the control, with increased doses, while, for the hundredth seed weigth (B), there was an increase in the amplitude of the distribution with the increase of the doses, and the gains were of the order of $76.6 ; 22.3$ and $21.9 \%$, respectively.

Figure 6 shows the levels of protein (A) and oil (B) in soybean seeds, with increasing variability due to gamma rays application, including the presence of outliers for both characters.

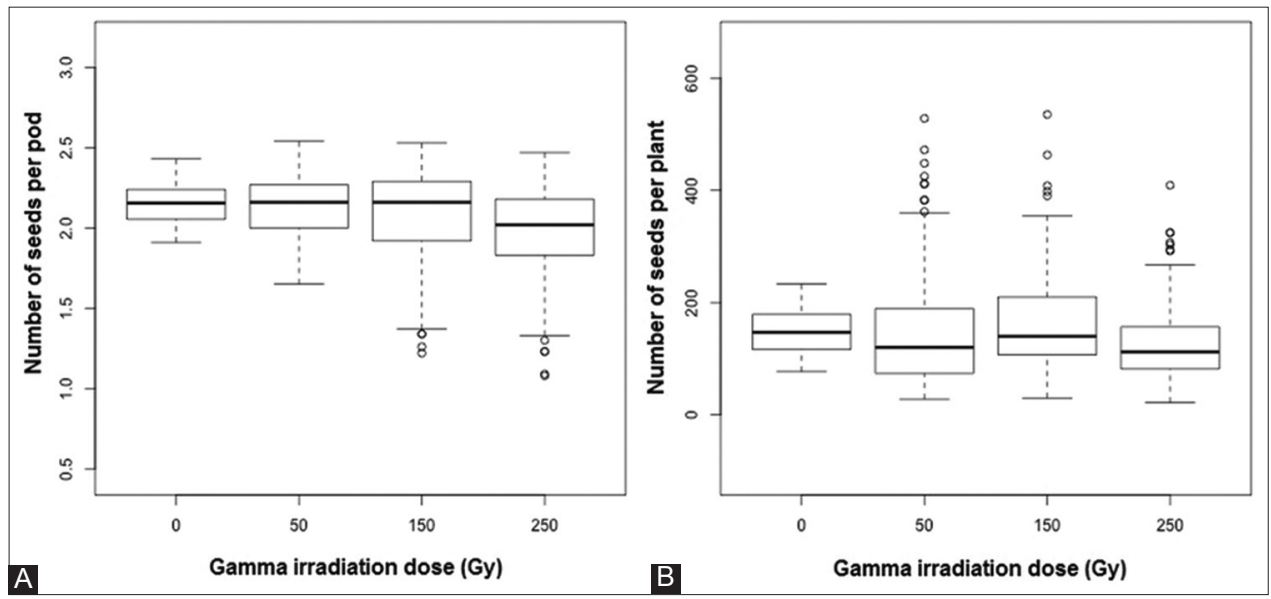

Fig 4. Boxplot for the number of seeds per pod (A) and number of seeds per soybean plant (B), submitted to doses of gamma radiation (Gy).

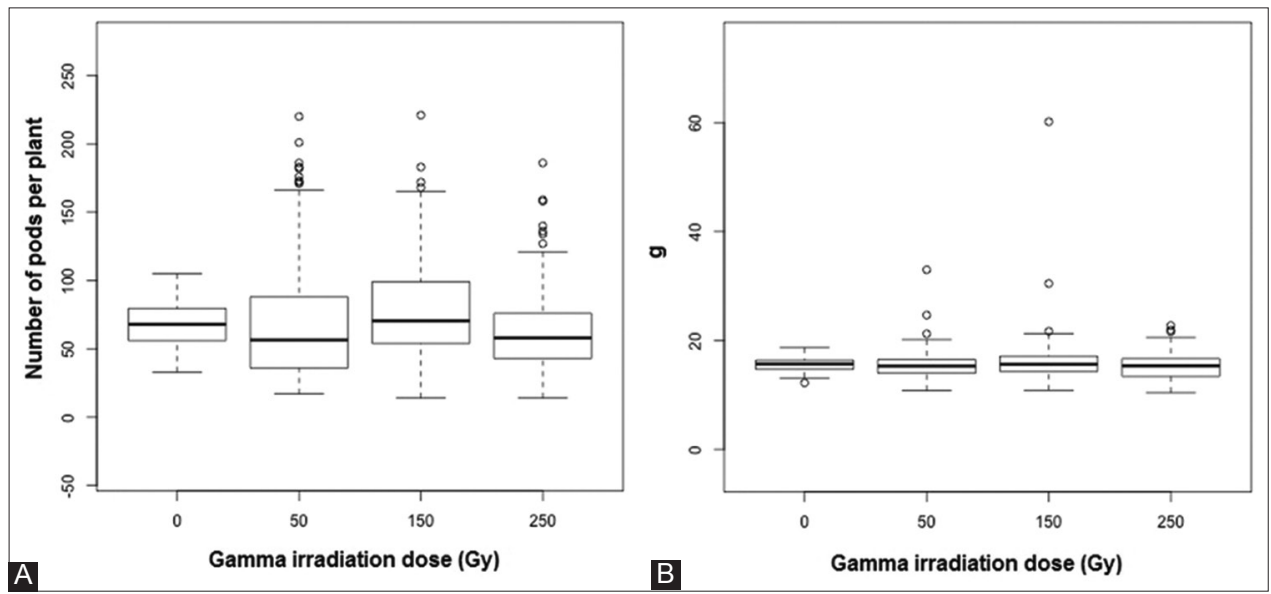

Fig 5. Boxplot of the number of pods per plant (A) and weight of one hundred seeds (B), submitted to gamma radiation doses (Gy). 


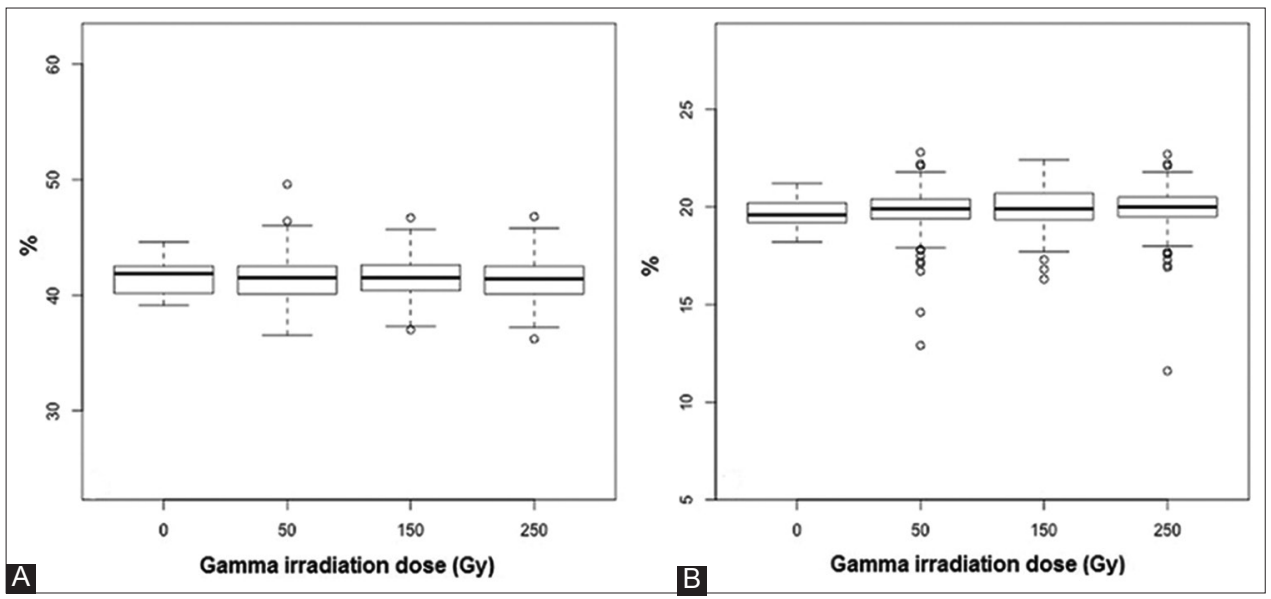

Fig 6. Boxplot of protein (A) and oil percentages (B) of soybean seeds submitted to doses of gamma radiation (Gy).

Protein and oil contents, along with yield, are the most important characteristics of soybean (Xu et al., 2015). In this way, any increase in these components is of substantial interest for the genetic improvement of the crop.

Comparing the plant of the control treatment (0 Gy) with the highest protein content $(44.2 \%)$, with the plant with the highest protein content of the other treatments, 50 , 150 and $250 \mathrm{~Gy}$, including the outliers, it was observed increments of the order of $11.2 ; 4.7$ and $4.9 \%$, respectively, indicating the possibility of gains in protein content when using gamma radiation. Similarly, comparing the values for the oil content in the different treatments, there is a possibility of gains in relation to the control, with observed increments of 7.5; 5.7 and 7.1\%, at doses of 50, 150 and 250 Gy, respectively.

A tendency of increase in the protein and a decrease in the oil contents were observed, when the frequencies of outliers were accounted. This negative trend between protein and oil is in line with the results obtained by Hymowitz et al. (1972), which report an inverse correlation between these substances in soybean seeds.

The increments for the different variables observed in the present study, may be credited to the use of gamma radiation and, the agronomic characteristics of lineage VX04-6828, in general, showed an improved performance with the application of gamma radiation from 50 to $150 \mathrm{~Gy}$.

Mudibu et al. (2012), evaluating soybean plants in the M2 generation with the application of 200 to $400 \mathrm{~Gy}$, observed a significant increase in grain yield and yield components. This result was confirmed by Tshilenge-Lukanda et al. (2013) when using 100 Gy on peanut seeds (Arachis hypogaea) and by Fontes et al. (2013), when using 50 Gy on cowpea seeds (Vigna unguiculata).
In summary, gains and losses in agronomic characteristics measured by the traditional soybean plant phenotyping of the present study were achieved by the action of gamma radiation. The effects are caused by the frequency of chromosomal abnormalities due to the use of gamma radiation, and when transmitted the next generations drive genome adaptation and evolution, with new benefits to the crop such as increased vegetative growth and better yield, but high doses induce DNA breakdown that can trigger genetic instability (El-Azab et al., 2018; De Veylder et al., 2003).

For the chemical composition of the seeds selected in each plant, a significant effect $(p<0.05)$ was observed for the carbohydrates (raffinose and sucrose) and lipids (linoleic acid and linolenic acid) at the applied gamma radiation doses (Figure 7).

Sucrose and raffinose carbohydrates content in the seeds increased as the gamma radiation doses increased. For lipids (linoleic and linolenic acid), the doses of 50 and 150 Gy cause small reductions in the contents of these compounds, with a slight increase with $250 \mathrm{~Gy}$, compared to the control. Gamma rays favor changes in biochemical pathways, disturb the synthesis of amino acids, lipids, nucleic acids, among other compounds, affect gas exchange, hormone balance and enzyme activity (Hameed et al., 2008; Jan et al., 2012). Therefore, the use of gamma radiation may be an important tool to generate mutations which may be used to develop varieties with new characteristics, even those not studied in the present work, such as disease resistance, cold tolerance and salinity and high quality, as has been shown by Gaafar et al., 2016.

Genetic improvement of the seed quality can take advantage on the genetic variability produced by new mutated alleles which can be selected based on the scoring of their components, that is, by the chemical composition of the 


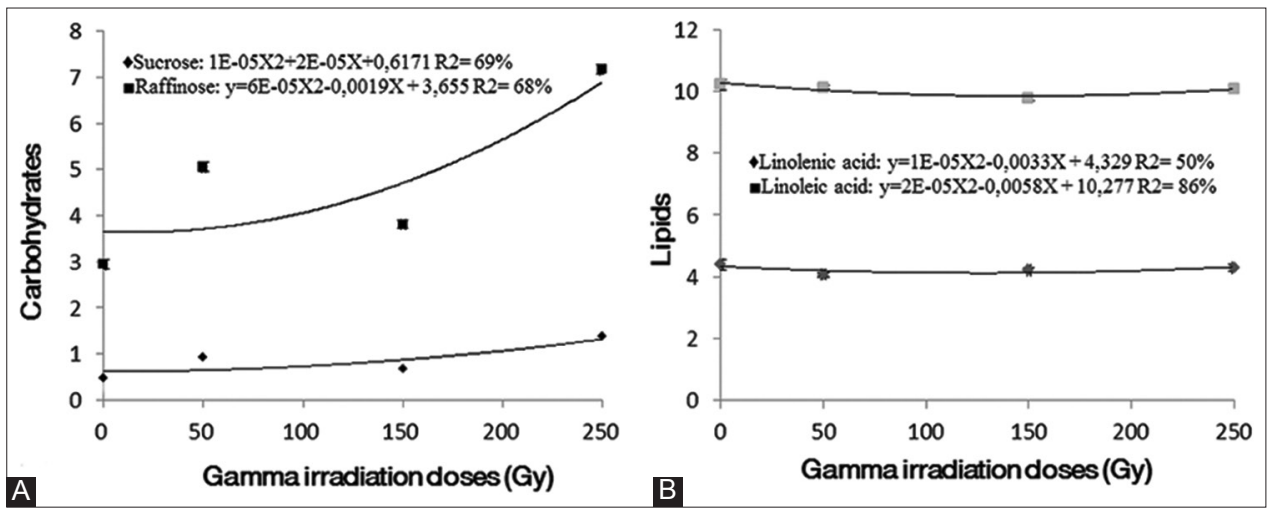

Fig 7. Carbohydrates (raffinose and sucrose (A)) and lipids (linoleic and linolenic acid (B)) percentages found in soybean seeds submitted to doses of gamma radiation (Gy).

Table 1: Variance of carbohydrate (raffinose and sucrose) and lipid (linoleic acid and linolenic acid) contents for soybean seeds from plants submitted to four doses of gamma radiation (Gy)

\begin{tabular}{lcccccccc}
\hline Doses (Gy) & \multicolumn{4}{c}{ Carbohydrates } & & \multicolumn{3}{c}{ Fatty acids } \\
\cline { 2 - 4 } \cline { 7 - 9 } & Sucrose & Raffinose & Stachyose & Total sugars & & Oleic & Linoleic & Linolenic \\
\hline 0 & 0,52 & 0,12 & 0,38 & 0,51 & & 0,17 & 0,09 & 0,40 \\
50 & 66,92 & 66,92 & 0,43 & 0,45 & & 0,33 & 0,07 & 0,72 \\
150 & 74,18 & 70,82 & 0,39 & 0,51 & & 0,44 & 0,10 \\
250 & 123,60 & 123,60 & 0,40 & 0,42 & & 0,43 & 0,09 & 0,90 \\
\hline
\end{tabular}

seeds (Vollmann and Jankowicz-Cieslak, 2017). It is worth mentioning that the chemical composition of soybean seeds is variable among cultivars (Delarmelino-Ferraresi et al., 2014).

It is evident that the variance within each applied dose (Table 1), that is, in the plant-to-plant variation, increases due to the influence of gamma rays applied in increasing doses. This allows a greater probability of identifying the presumed mutants. According to Ferreira (2009), the variance is extremely useful as a measure of variability, increasing as the differences (dispersion) between the elements of the set increases.

For Borém and Miranda (2013), the screening carried out from the M2 generation, as performed in the present study, allows limiting the physiological damage restricted to the M1 generation and guarantees the possible transfer of gene mutations and chromosomal aberrations to the next generation. Although, for some variables, the lineage under study presents less sensitivity to gamma radiation, according to the low increments observed; the use of the radiation allows better characterization of the plants by the evaluation of their progenies, which may indicate favorable alterations in some plants that can be used as potential parents in crossing programs.

\section{CONCLUSION}

The use of gamma radiation increases the variability in soybean, with consequent increase in the probabilities of identification of new mutants, useful to breeding programs that aim at better agronomic performance and gains in the composition of the seeds. Better results is observed when 50 to $150 \mathrm{~Gy}$ is applied on soybean dry seeds.

\section{ACKNOWLEDGMENTS}

This study was financed in part by the Coordenação de Aperfeiçoamento de Pessoal de Nível Superior - Brasil (CAPES) - Finance Code 001, and Conselho Nacional de Desenvolvimento Científico e Tecnológico (CNPq).

\section{Authors' contributions}

DACN conducted the research work, interpreted the data, and prepared the manuscript; CSS and NDP provided the guidance for experimental designand and help interpreted the data; VA and WRM critically reviewed the manuscript.

\section{REFERENCES}

Barnes, S. 1995. Effect of genistein on in vitro and in vivo models. J. Nutr. 125: 777-783.

Bazoni, C. H. V., E. I. Ida, D. F. Barbin and L. E. Kurozawa. 2017. Near-infrared spectroscopy as a rapid method for evaluation physicochemical changes of stored soybeans. J. Stored Prod. Res. 73: 1-6.

Bizeti, H. S., C. G. P. Carvalho, J. R. P. Souza and D. Destro. 2004. Path analysis under multicollinearity in soybean. Braz. Arch. Biol. Technol. 47: 669-676.

Borém, A. and G. V. Miranda. 2013. Melhoramento de Plantas. UFV, Viçosa, MG. 
Bruce, R. W., C. M. Grainger, A. Ficht, M. Eskandari and I. Rajcan. 2019. Trends in soybean trait improvement over generations of selective breeding. Crop Sci. 59: 1-10.

Costa, R. M. A., W. C. Lima, C. I. G. Vogel, C. M. Berra, D. D. Luche, R. Medina-Silva, R. S. Galhardo, C. F. M. Menck and V. R. Oliveira. 2001. DNA repair-related genes in sugarcane expressed sequence tags (ESTs). Genet. Mol. Biol. 24: 131-140.

Dall'Agnol, A. A. 2016. Embrapa Soja no Contexto do Desenvolvimento da Soja no Brasil: Histórico e Contribuições. Embrapa, Brasília, DF.

Delarmelino-Ferraresi, L. M., F. A. Villela and T. Z. Aumonde. 2014. Desempenho fisiológico e composição química de sementes de soja. Rev. Bras. Ciênc. Agrár. 9: 14-18.

De Veylder, L., J. Loubès and D. Inzé. 2003. Plant cell cycle transitions. Curr. Opin. Plant Biol. 6: 536-543.

Dixit, A. K., V. Kumar, A. Rani, J. G. Manjaya and D. Bhatnagar. 2011. Effect of gamma irradiation on lipoxygenases, trypsininhibitor, raffinose family oligosaccharides and nutritional factors of different seed coat colored soybean (Glycine max L.). Radiat Phys Chem. 80: 597-603.

El-Azab, E. M., M. Soliman, E. Soliman and A. Badr. 2018. Cytogenetic impact of gamma irradiation and its effects on growth and yield of three soybean cultivars. Egypt. J. Bot. 58: 411-422.

Ferreira, D. F. 2009. Estatística Básica. UFLA, Lavras, MG.

Fontes, L. S., P. B. Arthur and V. Arthur. 2013. Efeitos da radiação gama em sementes de feijão (Vigna unguiculata L.) visando o aumento de produção. Rev. Verde. 8: 11-14.

Gaafar, R. M., M. Hamouda and A. Badr. 2016. Seed coat color, weight and eye pattern inheritance in gamma-rays induced cowpea M2-mutant line. J. Genet. Eng. Biotechnol. 14: 61-68.

Hameed, A., T. M. Shah, B. M. Atta, M. A. Haq and A. Sayed. 2008. Gamma irradiation effects on seed germination and growth, protein content, peroxidase and protease activity, lipid peroxidation in desi and kabuli chickpea. Pak. J. Bot. 40: 1031-1041.

Hymowitz, T., F. I. Collins, J. Panczner and W. M. Walker. 1972. Relationship between the content of oil, protein, and sugar in soybean seed. Agron. J. 64: 613-616.

Jan, S., T. Parween, T. O. Siddiqi and X. Mahmooduzzafar. 2012. Effect of gamma radiation on morphological, biochemical, and physiological aspects of plants and plant products. Environ. Rev. 20: $17-39$.

Krzywinski, M. and N. Altman. 2014. Visualizing samples with boxplots. Nat. Methods. 11: 119-120.

Lande, N. H., S. K. Dhapke, S. R. Patil, R. A. Sayyad, K. N. Uikey, V. S. Jayade and G. A. Kankal. 2018. Genetic variability induced by gamma rays in M2 generation of soybean (Glycine max (L.) Merrill). J. Soils Crops. 28: 177-184.

Lee, K. J., J. B. Kim, S. H. Kim, B. K. Ha, B. M. Lee, S. Y. Kang and D. S. Kim. 2011. Alteration of seed storage protein composition in soybean Glycine max (L.) Merrill mutant lines induced by Y-irradiation mutagenesis. J. Agric. Food Chem. 59: 12405-12410.

Morita, R., S. Nakane, A. Shimada, M. Inoue, H. lino, T. Wakamatsu,
K. Fukui, N. Nakagawa, R. Masui and S. Kuramitsu. 2010. Molecular mechanisms of the whole DNA repair system: A comparison of bacterial and eukaryotic systems. J. Nucleic Acids. 3: 1-32.

Mudibu, J., K. K. C. Nkongolo, A. Kalonji-mbuyi and R. V. Kizungu. 2012. Effect of gamma irradiation on morpho-agronomic characteristics of soybeans (Glycine max L.). Am. J. Plant Sci. 3: 331-337.

Patil, G., J. Chaudhary, T. D. Vuong, B. Jenkins, D. Qiu, S. Kadam, G. J. Shannon and H. T. Nguyen. 2017. Development of SNP genotyping assays for seed composition traits in soybean. Int. J. Plant Genomics. 2017: 1-12.

R Development Core Team. 2015. R: A Language and Environment for Statistical Computing. Version 3.1.3. Vienna: R Foundation for Statistical Computing. Available from: http://www.R-project. org. [Last accessed on 2018 May 02].

Ramchander, S., R. Ushakumari and M. A. Pillai. 2015. Lethal dose fixation and sensitivity of rice varieties to gamma radiation. Indian J. Agric. Res. 49: 24-31.

Sarker, S., M. S. Rahman, M. R. Islam, S. Hasna and M. S. Islam. 2014. Effect of gamma radiation on morpho-physiological characters of soybean. J. Environ. Sci. Nat. Resour. 7: 25-30.

Sediyama, T. 2013. Tecnologia de Produção de Sementes de Soja. Mecenas, Londrina, PR.

Sediyama, T. 2016. Produtividade da Soja. Mecenas, Londrina, PR.

Tshilenge-Lukanda, L. T., A. Kalonji-Mbuyi, K. K. C. Nkongolo and R. V. Kizungu. 2013. Effect of gamma irradiation on morphoagronomic characteristics of groundnut (Arachis hypogaea L.). Am. J. Plant Sci. 4: 2186-2192.

Tulmann Neto, A., T. Peixoto, M. C. Alves, J. C. V. Oliveira, J. O. M. Menten and M. Athayde. 1995. Indução de mutação na cultivar de soja IAC-8 visando à obtenção de precocidade. Pesq. Agropec. Bras. 30: 237-244.

Verma, N., T. Izhar, M. Chakraborty and J. G. Manjaya. 2018. Mutation study of gamma ray in M3 generation of soybean (Glycine max. (L.) Merrill). J. Pharmacogn. Phytochem. 7: 3543-3547.

Vollmann, J. and J. Jankowicz-Cieslak. 2017. Utilizing NIRS for Qualitative and Nondestructive Identification of Seed Mutants in Large Populations. Available form: https://www.link.springer. com/content/pdf/10.1007/978-3-319-45021-6_12.pdf. [Last accessed on $2018 \mathrm{Jul} 27$ ].

Wee, C., M. Hashiguchi, G. Ishigaki, M. Muguerza, C. Oba, J. Abe, K. Harada and R. Akashi. 2018. Evaluation of seed components of wild soybean (Glycine soja) collected in Japan using near-infrared reflectance spectroscopy. Plant Genet. Resour. 16: 94-102.

Wickham, H. and L. Stryjewski. 2011. 40 Years of Boxplots. Vol. 29. p. 1-17. Available from: http://www.vita.had.co.nz/ papers/boxplots.pdf. [Last accessed on 2018 Jul 10].

Xu, X. P., H. Liu, L. Tian, X. B. Dong, S. H. Shen and L. Q. Qu. 2015 Integrated and comparative proteomics of high-oil and highprotein soybean seeds. Food Chem. 172: 105-116. 
Nobre, et al.

\section{SUPPLEMENTARY FIGURE}
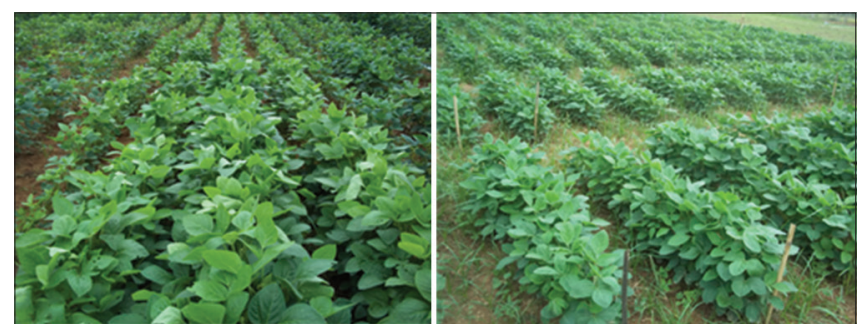

Supplementary Fig S1. Field production to M1 (A) and M2 generation (B) of soybean plants with seeds submitted to doses of gamma radiation (Gy). 